\title{
THE MOST IMPORTANT MICROTUBULE NATURAL INHIBITORS
}

\author{
Jiři Patočka ${ }^{1}$, Anna Strunecká ${ }^{2}$ \\ Purkyně Military Medical Academy, Hradec Králové: Department of Toxicology ${ }^{1 ;}$ Charles University in Prague: \\ Department of Physiology and Developmental Biology ${ }^{2}$
}

Summary: Natural microtubule inhibitors represent chemically very variegated family of structures with strong effect on cytoskeletal functions and the use of them is one of the most frequent therapeutic strategies for carcinoma treatment. The survey of the most important natural microtubule inhibitors is summarized in this paper.

Key words: Cytoskeleton; Microtubule; Inhibitor; Carcinoma; Minireview

\section{Introduction}

The cytoskeleton of eukaryotic cells is a filamentous network formed by microtubules, microfilaments and intermediate filaments. The cytoskeletal network is responsible for the mechanical properties of the cell that modulate functions such as cell shape, locomotion, cytokinesis, and translocation of organelles. Experimental evidence suggests that there are many important functions of dynamic cytoskeletal network besides the regulation of cellular mechanics. The cytoskeleton also provides connections between cellular structures and presents a large surface area for interactions of various proteins and signaling molecules. Modulation of cytoskeletal network may influence cell signaling, ion channels and intracellular calcium levels. The reorganization or degradation of all cytoskeletal filaments is associated with apoptosis. Cytoskeleton is thus essential for regulation of cellular functions, cell integrity, and viability. The relationships between direct mechanical effects of modulations of cytoskeletal structures and cellular functions remains to be elucidated.

The aim of this minireview is to.characterize the most important compounds of natural origin which interact with microtubules. Microtubules are tubulin polymers involved in many cellular functions (10), one of which being the formation of the mitotic spindle required for chromosome moving to the poles of the new forming cells during cell division (2). The importance of microtubules to cellular functions makes them a sensitive target for biological microtubule poisons. All compounds which interact with microtubules in the sense of their stabilization or disorganization are called microtubule inhibitors. They have cytotoxic effect and may kill the cell. Since microtubules are required to carry out mitosis in cell proliferation, microtubule inhibitors would primarily attack cancer cell which divides more frequently than healthy cell. Therefore many of them are very important anti-cancer compounds. The use of this poisons is one of the most frequent therapeutic strategies for carcinoma treatment. In addition to well known microtubule poisons such as vinblastin, colchicin, and taxol, already now many new natural toxic compounds are used as outstanding scientific tools in biological experiments and serve the purpose of model structures for synthesis new compounds with expected effect.

\section{Microtubule system}

Tubulin is a protein whose quaternary structure is composed of two polypeptide subunits, $\alpha$ - and $\beta$-tubulin. Several isotypes have been described for each subunit in higher eucaryots. Microtubule functions are based on their capacity to polymerize and to depolymerize. This process is a very dynamic and is attend with rapid shortening or elongation of this cell structures. Tubulin is a GTP-binding protein and the binding of this nucleotide to the protein is required for microtubule polymerization, whereas the hydrolysis of the GTP bound to polymerized tubulin is required for microtubule depolymerization. Microtubule stability in healthy cell is regulated by the presence of some proteins called microtubule-associated proteins (MAP) which facilitate microtubule stabilization. The cellular mechanisms regulating microtubule assembly is highly sensitive to the concentration of $\mathrm{Ca}^{2+}$. The low cytosolic $\mathrm{Ca}^{2+}$ level characteristic of the resting state of most eucaryotic cells promotes microtubule assembly, while the localized increase in $\mathrm{Ca}^{2+}$ cause microtubule disassembly (13). Microtubules forms through polymerization of protein dimers, consisting of one molecule each of $\alpha$ - and $\beta$-tubulin. Dimer and polymer are in a state of dynamic equilibrium, so that the network can respond flexibly and quickly to functional requirements. The polymer forms a fine, unbranched cylinder, usually with internal and external diameters of 14 and $28 \mathrm{~nm}$, respective- 
ly, the so called microtubule (Fig. 1) (22). Assembly is initiated by the binding together of $\alpha$, $\beta$-dimers to form short protofilaments, 13 of which subsequently arrange themselves side by side to form the microtubule. Subsequent growth of the microtubule is polar, occurring mainly at the so-called plus end of the protofilaments through the addition of further dimers. Addition involves GTP, which is bound to the dimer, being cleaved to GDP, which remains attached to the tubulin. The binding site for GTP is on the $\beta$-subunit. When the cell becomes enriched with GTP-tubulin dimers, hydrolysis to GDP-tubulin falls behind the rate of assembly and an $\alpha, \beta$-tubulin-GTP cap forms at the plus end of the protofilaments blocking further growth of the microtubule.

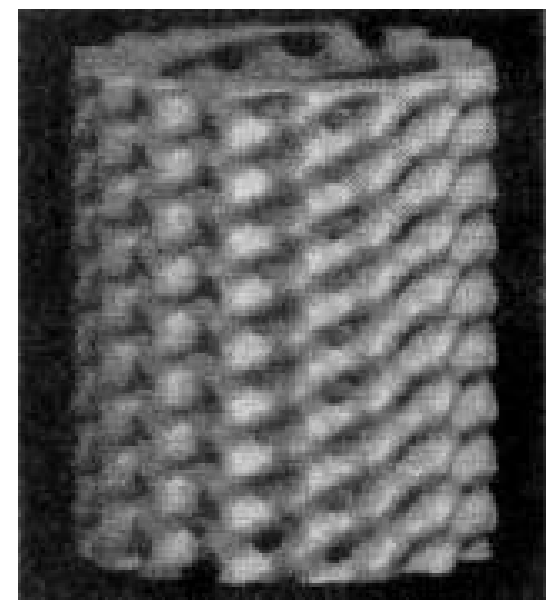

Fig. 1: The structure of microtubule polymer cylinder, usually with internal and external diameters of 14 and $28 \mathrm{~nm}$, respectively.

\section{The classification of microtubule natural inhibitors}

Microtubule inhibitors represents chemically very variegated group of compounds from different biological sources with strong effect on cytoskeletal functions and strong toxicity. Microtubule functions in cell depend on the capacity of tubulin to polymerize or the capacity of microtubules to depolymerize.

Compounds which are able to influent these processes, i.e. microtubule inhibitors (also anti-tubulin agents, antimitotic agents, etc.), can be divided into four group according to their mechanism of action. 1. Compounds which bind to GTP site, 2. compounds which bind to colchicine site, 3 . compounds which influence as microtubule-stabilizing agents, and 4. compounds which do microtubule network disorganization.

\section{Compounds bind to GTP site}

Typical representatives of this group of microtubule poisons are vinca alkaloids, compounds derived from
Catharanthus roseus, a plant from warm climate. The most important compounds of this group are vinblastine and vincristine, compounds composed from a tetracyclic structure of catharantine and a pentacyclic structure of vindoline (41). Both structures appear to be important for both vinblastine and vincristine activity. The analysis of the localization of vinblastine-binding site on tubulin has indicated that it occurs at the central region of the beta-tubulin subunit (37). In this region is also GTP binding site and it has been shown that vinca alkaloids and other related molecules can prevent the binding of GTP to tubulin. Vinblastine is mainly useful for treating lymphocytic and histiocytic lymphoma, Hodkin's disease, Kaposi's sarcoma, and advanced breast or testicular cancer. Vincristine is used mainly to treat acute leukemia, neuroblastoma, rhabdomyosarcoma, Hodkin's disease and other lymphomas. Semisynthetic derivatives of vinca-alkaloids with lower toxicity are now at different phases of clinical trial, for example vindesine or vinorelbin, which are tested in breast cancer. Other microtubule inhibitors are dolastin isolated from the sea hare (Dolabella auricularia), compound with both pyrrolidine and thiazoline moiety in the molecule, griseofulvin, an antibiotic produced by Penicillium griseofulvum, maytansine, a macrolide compound from rainforest plant Maytenus serrata and others family Celastraceae (34), famous ethnomedicine known in western Amazonia as chuchuhuasi.

Halichondrin $\mathbf{B}$ is the most potent compound of a class of polyether macrolides isolated in low yield from four different sponge genera - Axinella, Halichondra, Lissodendoryx, and Phakellia (35). Halichondrin $\mathbf{B}$ acts on tubulin by similar mechanism as vinblastine $(4,11)$. From the fungus Rhizopus chinensis was isolated other cytotoxic macrolide compound, rhizoxin, with significant antineoplastic activity in several murine and human tumor models (6). Cryptophycin $\mathbf{A}$ is a new antimicrotubule agent, active against some drug-resistant cells (44) and with potent antiproliferative effect and with excellent antitumor activity against mammary, colon, and pancreatic adenocarcinomas (33). A highly cytotoxic macrocyclic lactone polyether has been isolated from a Spongia species and named spongistatin. This compound inhibited the glutamate-induced polymerization of tubulin and it is a potent inhibitor of the binding of vinblastin and GTP to tubulin (3).

\section{Compounds bind to colchicine site}

Colchicine is alkaloid found in the autumn crocus ( $\mathrm{Col}$ chicum autumnale) and also in other plants. Autumn crocus was used in the antiquity for the treatment of gout, but the main interest for the study of colchicine came when it was observed that this drug could stop cell proliferation in mitosis, by preventing the formation of the mitotic spindle. Structurally, colchicine is a tropolone derivative with three rings $\mathrm{A}, \mathrm{B}$ and $\mathrm{C}$. Ring $\mathrm{A}$ is a six-carbon ring with three metoxy groups, whereas B and C are seven-carbon rings (19). Several unfavorable characteristics have been observed for 
the binding of colchicine to tubulin. The reaction is very slow, temperature-dependent and essentially irreversible. The binding of colchicine to tubulin becomes faster and reversible when a methyl group replaces the acetyl group present on the amine of the $\mathrm{B}$ ring, yielding the compound known as colcemide.

On the same site as colchicin bind also podophyllotoxin, plant compounds obtained from Podophyllum peltatum. Podophyllotoxin is a tetracyclic compound with four rings $\mathrm{A}, \mathrm{B}, \mathrm{C}$, and D, linked to an aromatic ring with three methoxy groups. This alkaloid is, like colchicine, a drug that prevents microtubule polymerization. It has been used for topic treatment of some benign skin tumors. Some synthetic derivatives of podophyllotoxin apear to be more active than podophyllotoxin alone in the treatment of leukemias and solid tumors.

\section{Microtubule-stabilizing compounds}

Among these compounds, the best known one is taxol (paclitaxel), tetracyclic compound obtained from the bark of the Pacific yew (Taxus brevifolia). In the structure of taxol there are two aromatic rings and a tetracyclic-structure containing an oxetane ring which is required for the activity of the drug (18). The primary action of this compound is to stabilize microtubules, preventing their depolymerization. In this way taxol should block proliferating cells between $G_{2}$ and mitosis, during the cell cycle. The binding of taxol appears to occur at different localizations at the amino terminal of $\beta$-tubulin, but binding to the middle region of a alpha-tubulin has also been reported (28). Taxol has been used mainly for the treatment of breast and ovarian cancer but also it has been tested for other types of tumors such as lung cancer, head and neck cancer and melanoma. Several disadvantages have been indicated for application of this very actual anti-cancer compound. One of them, the relative low amount that can be obtained from the bark of the Pacific yew and its relatively rare incidence restrict to the forests of the Pacific Northwest of the USA and Canada. This problem has been partially solved by chemical synthesis of this compound (32). Another disadvantage is the low solubility of taxol in water, thus, this drug must be delivered dissolved in oil and this solvent could effect to cardiad functions or promote allergic reactions. Also, this problem has been partially solved by synthesizing some taxol analogs with a higher solubility in water (32). Interesting semisynthetic analogue of taxol with clinical use is docetaxel (Taxotere), compound which contains a taxane ring linked to an oxetan ring at positions C-4 and C-5 and to an ester side chain at C-13.

A new class of microtubule-stabilizing compounds have been isolated from the bacterium Sorangium cellulosum. These macrolide compounds were caled epothilones, because their typical structural units are epoxide, thiazole, and ketone (27,42). Epothilone occurs in two structural variations, epothilone $\mathbf{A}$ and epothilone $\mathbf{B}$, the latter containing an additional methyl group (23) . Epothilone $\mathbf{A}$ is the main product of bacteria metabolism, the yield of epothilone B amounting to 20-30 per cent of the yield of epothilone A. Despite the small different in chemical structure, in most test systems epothilone $\mathbf{B}$ has been approximately ten-time more effective. These compounds show a striking effect on stabilizing polymerization of microtubules and they are easily obtained on large scale by a fermentation process (14). Both epothilones show a very narrow spectrum of activity (19) and halts cells, as does taxol, in the $G_{2}-M$ phase (23). The Total synthesis of epothilones was reported in many laboratories $(5,43,45,48)$.

Of recent interest is the discovery of the marine-derived compound, discodermolide, whose anti-mitotioc mechanism of action includes the polymerization and stabilization of microtubules in a method analogous to that observed with the structurally unrelated compound taxol $(29,30)$.

\section{Compounds with disorganization effect on microtubule network}

Some natural marine compounds with anti-tumoral activity were found to disorganise the microtubule network (12). There are ecteinascidin $\mathbf{7 4 3}$, tetrahydroisoquinoline alkaloid isolated from the marine ascidian, Ecteinascidia turbinate, $(15,24)$, several members of the family of lamellarins, for example lamellarin $\mathbf{Q}$, polyaromatic alkaloids isolated form marine tunicates belonging to the genus Didemnum (36), as well as cyclic depsipeptides of the family didemnins; the most known compound of this family is didemnin B (31). Didemnins were isolated from the marine tunicates Tridemnum solidum and Aplidium albicans (47) and many very biologically active compounds of this family were prepared also synthetically or semisynthetically (40).
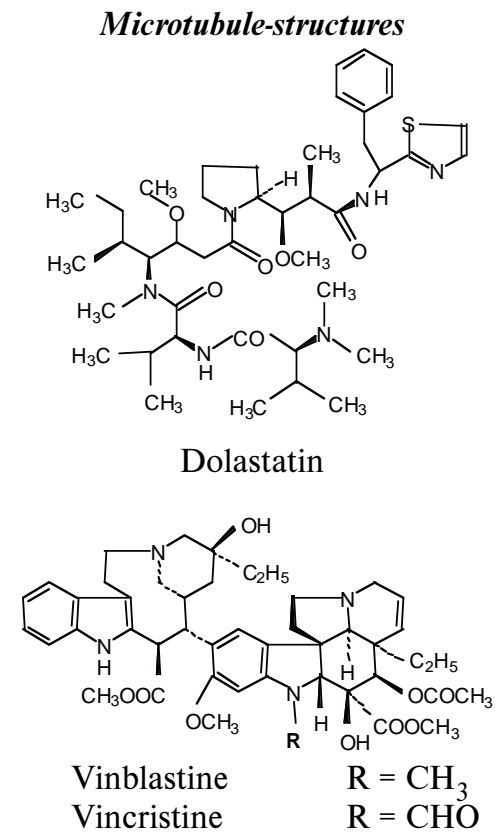


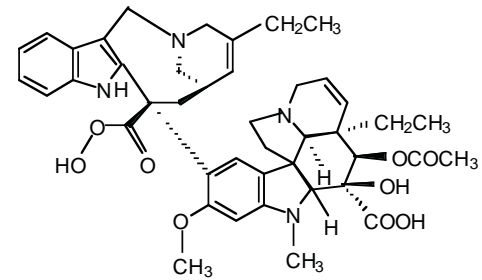

Vinorelbin

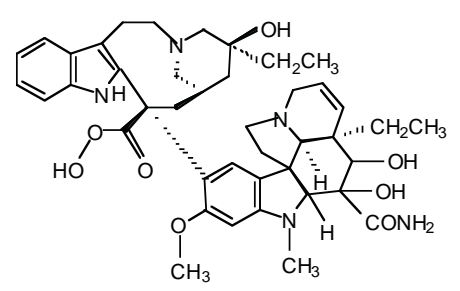

Vindesine

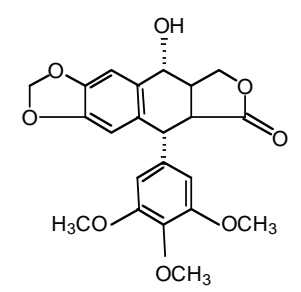

Podophyllotoxin

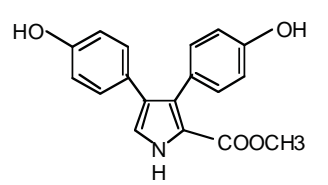

Lamellarin Q

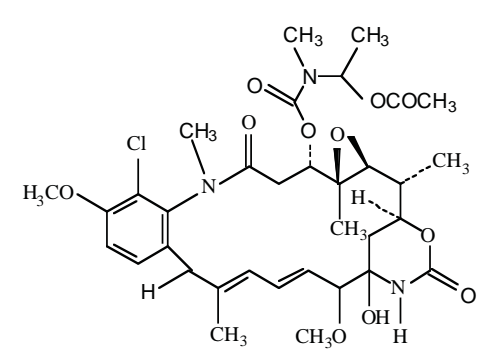

Maytansin

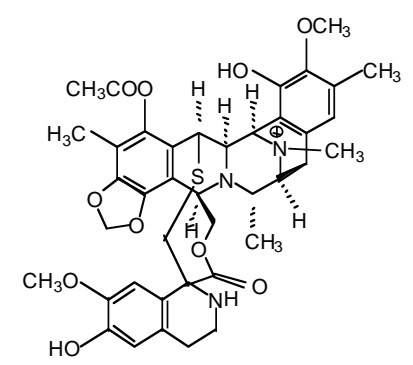

Ecteinascidin 741

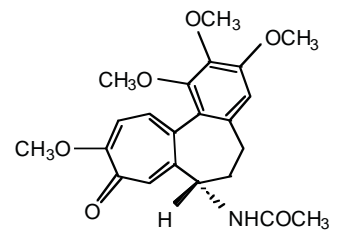

Colchicine

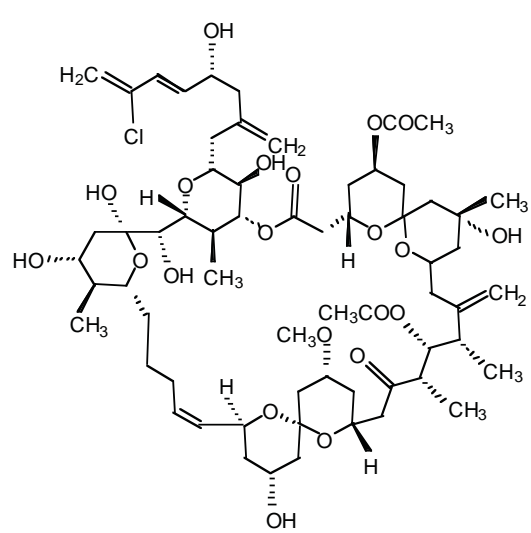

Spongistatin

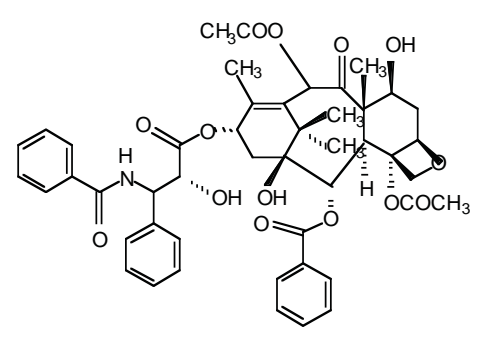

Taxol

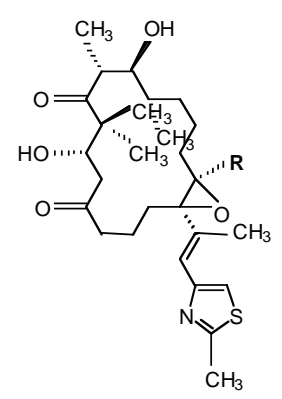

Epothilone A $\quad \mathrm{R}=\mathrm{H}$ Epothilone B $\quad \mathrm{R}=\mathrm{CH}_{3}$

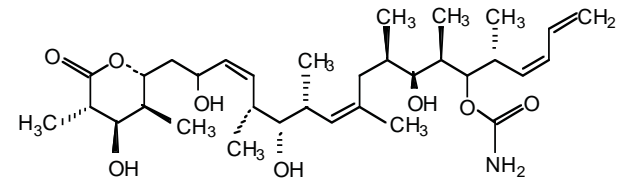

Discodermolide

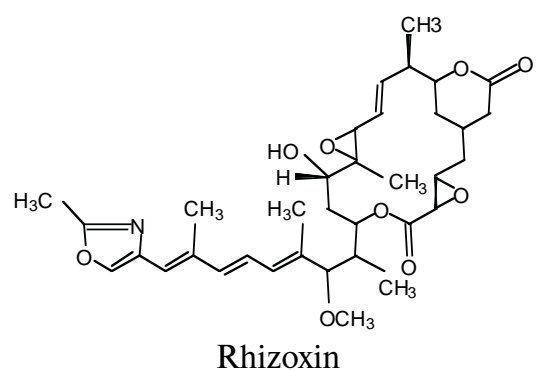

Rhizoxin

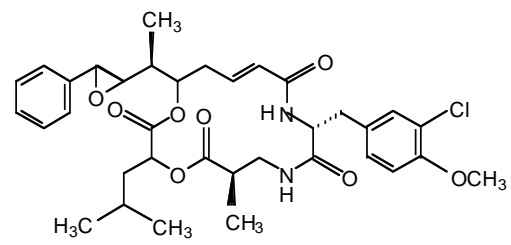

Cryptophycin A

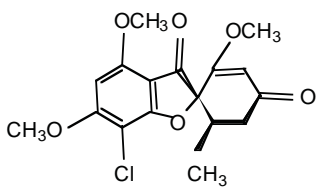

Griseofulvin

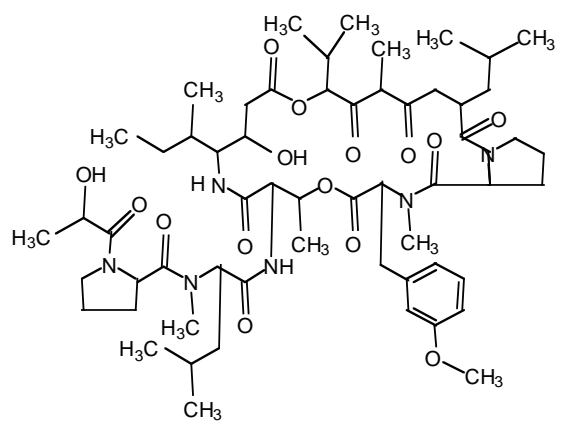

Didemnin B

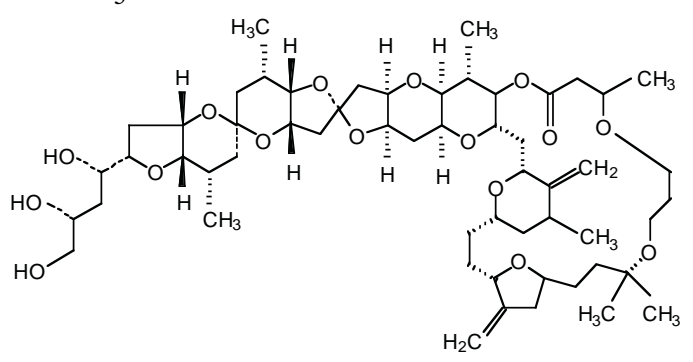

Halichondrin B 


\section{Applications of microtubule inhibitors in future research}

There are many demonstrations that mechanical forces mediated by cytoskeleton play a vital role in assembling cellular structures. Moreover, recent experimental evidence demonstrate the multiple interactions between cytoskeletal structures and ion channels, calcium fluxes, and events connected with signal transduction. The process of microtubule assembly proceeds in a cell-free system and the effects of various inhibitors can be thus studied even in the test tube. The use of various natural microtubule inhibitors provides the possibility to study the mechanisms of assembly and disassembly of cytoskeletal structures as well as the role of cytoskeleton in spatial and temporal integration of vital cell functions.

The regulation of microtubule assembly depends on the ability of tubulin heterodimers to bind GTP. The GTP bound to the $\beta$-polypeptide is hydrolyzed to GDP plus phosphate (26). The course of assembly and disassembly of microtubules is therefore affected by the action of GTPases. A number of heterotrimeric GTPases or small GTPases of the rho family move on the cytoskeleton after cell activation $(9,46]$. Moreover, a direct transfer of GTP from tubulin to the $\alpha$ subunit of the Gs and Gi protein has been reported (39). On the other hand it has been reported that microtubules can also assemble in the presence of nonhydrolyzable GTP analogues. These observations may demonstrate that such interactions do not entirely serve to microtubule reorganization, but may be also related with cell signaling pathways. The use of various microtubule inhibitors which bind to GTP site could contribute to the study of this suggested role of microtubules in eucaryotic cells.

Polymerization of tubulin heterodimers is regulated by $\mathrm{Ca}^{2+}$ concentration. Under low $\mathrm{Ca}^{2+}$ concentration characteristic for the cytoplasm of most eucaryotic cells, much of the tubulin is assembled into microtubules. Localized increases in $\mathrm{Ca}^{2+}$ concentration cause microtubule disassembly (13). The alteration of microtubule structure by colchicin has been reported to enhance the activity of $\mathrm{Ca}^{2+}$ channels in Lymnaea neurons and mammalian hippocampal pyramidal neurons (25). An intact microtubule system is required for the $\mathrm{IP}_{3}$ - dependent $\mathrm{Ca}^{2+}$ release from intracellular stores (17). The inhibitory effect of colchicin in saponin-permeabilized platelets has been reported (8).

Disruption of microtubules by colchicin has been reported to increase conductance of $\mathrm{Cl}^{-}$channels in skeletal muscle (21), and decreased conductance of snake twich fibre end plates (20). The mechanism of this functional change and the role of cytoskeletal structures in the transmembrane ion transport is not known. On the other hand, taxol had no effect on the ion channels in hippocampal neurons (38).

Disruption of microtubular structures by taxol leads to increased phoshorylation and to the cell death $(7,16)$. Degradation of tubulin can occur very early in the course of apoptosis. It has been reported in neuronal cells treated with glutamate (1). Although the relation between the microtubule system and the apoptotic program remains unclear, the disruption of microtubule turnover undoubtedly leads to cell death.

\section{Conclusions}

Microtubule inhibitors from different natural sources represents chemically very variegated group of compounds with strong effect on cytoskeletal functions and strong toxicity. The use of this poisons is one of the most frequent therapeutic strategies for carcinoma treatment. Drugs like vinblastine and taxol, have wide clinical use, although they have some drawbacks. The discovery of new compounds such epothilones, halichondrins, didemnins, etc., could overcome some of the problems found with the use of the earlier drugs. In addition, already now these natural toxic compounds are used as outstanding scientific tools in biological experiments and serve the purpose of model structures for synthesis new compounds with expected effect.

We would like to thank Miss Katerina Ševčiková from the Institute of Chemical Technology, Prague, for technical assistance.

\section{References}

1. Ancarcrona M, Zhivotovsky B, Holmstrom $\mathrm{T}$ et al. Lamin and beta-tubulin fragmentation precede chromatin degradation in glutamate-induced neuronal apoptosis. Neuroreport 1996;7:2659-64.

2. Avila J. Microtubule dynamics. FASEB J 1990;4:3284-90

3. Bai RL, Cichacz ZA, Herald CL et al. Spongistatin 1, a highly cytotoxic, spongederived, marine natural product that inhibits mitosis, microtubule assembly, and the binding of vinblastine to tubulin. Mol Pharmacol 1993;44:757-66.

4. Bai RL, Paull KD, Herald CL et al. Halichondrin B and homohalichondrin B, marine natural products binding in the vinca domain of tubuline. Discovery of tubulin-based mechanism of action by analysis of differential cytotoxicity data. J Biol Chem. 1991;266:15882-9.

5. Balog A, Meng D, Kamenecka T et al. Totalsynthese von (-)-Epothilon A. Angew Chem 1996;108:23-4.

6. Bissett D, Graham MA, Setanoians A et al. Phase I and pharmacokinetic study of rhizoxin. Cancer Res 1992;52: 2894-8.

7. Blagosklonny MV, Giannakakou P, Eideiry W et al. Raf-1/ bcl-2 phosphorylation: a step from microtubule damage to cell death. Cancer Res 1997:57:130-5.

8. Bourguignon LY, Iida A, Jin $\mathrm{H}$. The involvement of the cytoskeleton in regulating $\mathrm{IP}_{3}$ receptor-mediated internal $\mathrm{Ca}^{2+}$ release in human blood latelets. Cell Biol Int 1993; 17:751-8.

9. Drobak BK, Watkins PA, Bunney TD et al. Association of multiple GTP-binding proteins with the plant cytoskeleton and nuclear matrix. Biochem Biophys Res Commun 1995;210:7-13.

10. Dustin P. Microtubules, $2^{\text {nd }}$ ed., Springer-Verlag, Berlin 1984.

11. Fodstat O, Breistol K, Pettit GR. et al. Comparative antitumor activities of halichondrins and vinblastine against human tumor xenografts. J Exp Ther Oncol 1996;1:119-25.

12. Garcia-Rocha M, Garcia-Gravalos MD, Avila J. Characterisation of antimitotic products from marine organisms that disorganise the microtubule network: ecteinascidin 743, isohomohalichondrin B and LL-15. Br J Cancer 1996;73:875-83.

13. Gelford VJ, Bershadski AD. Microtubule dynamics: mechanism, regulation, and function. Ann Rev Cell Biol 1991; 7:93-116.

14. Gerth K, Bedorf N, Höfle H et al. Epothilons A and B: antifungal and cytotoxic compounds from Sorangium cellulosum (myxobacteria). Production, physicochemical and biological properties. J Antibiot 1996;49:560-3.

15. Ghielmini M, Colli E, Erba E et al. In vitro schedule-dependency of myelotoxicity and cytotoxicity of Ecteinascidin 743 (ET-743). Ann Oncol 1998;9:989-93.

16. Haldar S, Basu A, Croce $\mathrm{CM}$. Bcl2 is the guardian of microtubule integrity. Cancer Res 1997;57:229-33.

17. Hajnoczky G, Lin C, Thomas APOD. Luminal communication between intracellular calcium stores modulated by GTP and the cytoskeleton. J Biol Chem 1994;269: 10280-7. 
18. Hamel E. Interactions of tubulin with small ligands in microtubule proteins. In: Avila J, ed. CRC Press Inc, Boca Raton, 1990,89-91.

19. Hamel E. Antimitotic natural products and their interactions with tubulin. Med Res Rev 1996;16:207-31.

20. Hardwick JC, Parsons RL. Requirement of a colchicin-sensitive component of the cytoskeleton for acetylcholine receptor recovery. Br J Pharmacol 1995;114:442-6.

21. Haussler U, Rivet BM, Fahlke C et al. Role of cytoskeleton in the regulation of $\mathrm{Cl}^{-}$channels in human embryonic skeletal muscle cells. Pflugers Arch 1994;42830.

22. Horwitz AF. Integrins an health. Scient Am 1997;276:46-53.

23. Höfle G, Bedorf N, Steinmetz H et al. Epothilone A and B - novel 16-membered macrolides with cytotoxic activity: isolation, crystal structure, and conformation in solution. Angew Chem Intern Ed 1996;35:1567-9.

24. Izbicka $\mathrm{E}$, Lawrence $\mathrm{R}$, Raymond $\mathrm{E}$ et al. In vitro antitumor activity of the novel marine agent, ectainascidin-743 (ET-743, NSC-648766) against human tumors explained from patients. Ann Oncol 1998;9:981-7.

25. Johnson BD, Byerly L. A cytoskeletal mechanism for $\mathrm{Ca}^{2+}$ channel metabolic dependence and inactivation by intracellular $\mathrm{Ca}^{2+}$. Neuron 1993;10:797-804.

26. Kirschner M, Mitchison T. Beyond self-assembly: from microtubules to morphogenesis. Cell 1986;45:329-42.

27. Kowalski RJ, Giannakakon P, Hamel E. Activities of the microtubule stabilizing agents epothilones A and B with purified tubulin and in cells resistant to paclitaxel (taxol). J Biol Chem 1997;272:2534-41.

28. Loeb C, Combeau C, Ehret-Sabatier L et al. [3H] (azidophenyl) ureido taxoid photalabels peptide aminoacids 281-304 of alpha-tubulin. Biochemistry 1997;36: 3820-2.1994;36:630-634

29. Longley RE, Caddigan D, Harmody D et al. Discodermolide: A new marine-derived immunosuppressive compound. I. In vitro studies. Transplantation 1991;52:650-6.

30. Longley RE, Caddigan D, Harmody D et al. Discodermolide: A new marine-derived immunosuppressive compound. II. In vivo studies. Transplantation 1991;52:656-61.

31. Mayer SC, Carroll PJ, Joullie MM. The cyclic depsipeptide backbone of the didemnins. Acta Crystallogr C 1995;15:1609-14.

32. Nicolau KC, Yang Z, Liu JJ et al. Total synthesis of taxol. Nature 1994;367: 630-4.

33. Panda D, Himes RH, Moore RE et al. Mechanism of action of the unusually potent microtubule inhibitor cryptophycin 1. Biochemistry 1997;36:12948-53.

34. Patočka J, Jahodár L. Obsahové látky čeledi rostlin Celastraceae. Chem Listy. In print.

35. Pettit GR, Herald CL, Boyd MR et al. Isolation and structure of the cell growth inhibitory constituents from the western Pacific marine sponge Axinella sp. J Med Chem 1991;34:3339-40.
36. Quesada AR, Garcia Gravalos MD, Fernandez Puentes JL. Polyaromatic alkaloids from marine invertebrates as cytotoxic compounds and inhibitors of multidrug resistance caused by P-glycoprotein. Br J Cancer 1996;74:677-82.

37. Rai SS, Wolf J. Localization of the vinblastine-binding site on beta-tubulin. J Biol Chem 1996;271:14707-11.

38. Rosenmund C, Westbrook GL. Calcium-induced actin depolymerization reduces NMDA channel activity. Neuron 1993;10:805-14.

39. Roychowdhury S, Rasenick MM. Tubulin-G protein association stabilizes GTP binding and activates GTPase: cytoskeletal participation in neuronal signal transduction. Biochemistry 1994;33:9800-5

40. Sakai R, Rinehart KL, Kishore V et al. Structure-activity relationships of the didemnins. J Med Chem. 1996;39:2819-34.

41. Saxton JE (Ed): Monoterpene Indole Alkaloids. Suppl. 4, Wiley 1994, 578.

42. Schinzer D. Epothilones - new promising microtubule-stabilizing natural products with taxol-like biological activity. Eur Chem Chronicle 1996;1:7-10.

43. Schinzer D, Limberg A, Bauer A et al. Totalsynthese von (-)-Epothilon A. Angew Chem 1997;109:543-4.

44. Smith CD, Zhang X, Mooberry S et al. Cryptophycin: a new antimicrotubule agent active against drug/resistant cells. Cancer Res 1994;54:3779-84.

45. Su DS, Meng D, Bertinato $P$ et al. Totalsynthese von (-)-Epothilon B: eine Erweiterung der Suzuki-Kupplung und Erkenntnisse ber StrukturWirkungsbeziehungen der Epothilone. Angew Chem 1997;109:775-7.

46. Tapon A, Hall A. Rho, rac and Cdc42 GTPases regulate the organization of the actin cytoskeleton. Curr Opin Cell Biol 1997;9:86-92

47. Urdiales JL, Morata P, Nunez de Castro I et al. Antiptoliferative effect of dehydrodidemnin B (DDB), a depsipeptide isolated from Mediterranean tunicates. Cancer Lett 1996;102:31-7.

48. Yang Z, He Y, Vourloumis D et al. Die Totalsynthese von Epothilone A: der Zugang durch Olefinmetathese. Angew Chem 1997;109:170-2.

\section{Submitted January 1999 \\ Accepted April 1999}

Doc. RNDr. Jiři Patočka, DrSc., Purkyně Military Medical Academy,

Department of Toxicology, 50001 Hradec Králové, Czech Republic. e-mail: patocka@pmfhk.cz 